\title{
A relação entre o conceito de ruas completas e a Política Nacional de Mobilidade Urbana: aplicaçáo a um projeto viário em Natal-RN, Brasil
}

Gabriel Valença. Instituto Superior Técnico, Lisboa, Portugal.

Enilson Santos. Universidade Federal do Rio Grande do Norte, Natal, Brasil.

RESUMO | A maior ocorrência de congestionamentos viários e os agravos à saúde pública e da redução da qualidade ambiental urbana, são fatos notórios produzidos pela ampliação do uso de automóveis nas cidades brasileiras. A conscientização da sociedade em torno desse tema resultou que fosse sancionada a Lei Federal 12.587/2012, que instituiu a Política Nacional de Mobilidade Urbana (PNMU), com o objetivo de elaborar políticas e planos locais de mobilidade sustentável. Neste artigo, os princípios, objetivos e diretrizes da PNMU são cotejados com os princípios projetuais derivados das complete streets, já estabelecido e largamente utilizado na América do Norte para reorganização de redes viárias. Verifica-se que o conceito exibe conformidade à PNMU e que, portanto, pode ser uma medida de política e uma ferramenta projetual que apoie a consecuçáo dos objetivos da Lei. Conclui-se o artigo com uma aplicação dos princípios das complete streets a um tramo viário em Natal, RN, Brasil.

PALAVRas CHAVE | desenvolvimento sustentável, mobilidade, planejamento urbano.

ABSTRACT | The increase in the number of cars used in Brazilian cities resulted in an aggravation of road congestion, impacts on public health, and environmental quality. The awareness around this issue resulted in the decreed of the Law 12.587/2012, which led to the National Urban Mobility Policy (PNMU). In this paper, the principles, objectives and guidelines of the PNMU are compared with the design principles of complete streets policies, already established and widely used in North America for the reorganization of road networks. It is found that the concept exhibits compliance to the PNMU and that it can be a policy measure and a design tool that supports the achievement of the objectives of the Law. The article concludes with an application of the principles of complete streets on a road in Natal, RN, Brazil.

KEYWORDS | sustainable development, mobility, urban planning. 


\section{Introduçáo}

A partir das décadas de 1960 e 1970, ganhou corpo a contestaçáo do design tradicional de vias urbanas, incidindo sobre a suposta eficiência econômica da fluidez do tráfego automobilístico e a maior compreensão de escopo e escala das externalidades socioambientais negativas a ela associadas (Banister, 2008; Litman, 2017; Suzuki, Cervero, \& Iuchi, 2013). Percebeu-se, então, que a dotação crescente de infraestruturas voltadas (quase que) exclusivamente para a mobilidade automobilística se torna insustentável a médio-longo prazo.

A partir daí, consolidou-se o entendimento técnico-acadêmico a respeito da importância de descentralizar os modos de transporte, na direção de um conceito de "humanização da via" (McCann, 2013), tributário de contribuiçóes que se originavam de práticas de traffic calming e esquemas de woonerven que passaram a ser sistematizadas na literatura técnico-científica por autores como Hass-Klau (1990, 1992), por exemplo. Nesse âmbito, as ruas passariam a ter um papel náo só de locomoção, mas também social, de vivência e até econômica, o que supunha - no campo técnico das infraestruturas de transporte urbano - intervençóes ancoradas principalmente na moderação de volumes e velocidades de tráfego.

Os desdobramentos teórico-conceituais e projetuais de tal abordagem deram origem a ideias-força, como as de "pedestrianização dos centros urbanos", "cidades para pessoas" ou "bairros vivenciáveis". Especificamente, na América do Norte da década inicial do século xxi, aquele legado intelectual e de realizaçóes concretas de quase 40 anos foi apropriado na formulaçáo progressiva do conceito de complete streets (Smart Growth America, n.d.a), expressão traduzida no Brasil para "ruas completas". Definia-se ali ruas completas como ruas dirigidas a todos os usuários e que, portanto, acarretam mais mobilidade e segurança para pedestres, ciclistas, usuários de transporte coletivo e automobilistas de todas as idades, limitaçóes e habilidades (Toronto Centre for Active Transportation, 2012). A partir de então, diversas cidades estadunidenses e canadenses têm usado este conceito para reprojetar e revitalizar ruas e espaços públicos: a National Complete Streets Coalition registra que, entre 2004 e o presente, 1.140 agências públicas nos EUA, em níveis estadual, regional ou local, adotaram políticas baseadas no conceito de ruas completas, totalizando cerca de 1.200 intervençôes (Smart Growth America, n.d.b). As ruas completas estão sendo implementadas em cidades norteamericanas, como Nova Iorque, Chicago, Boston, Vancouver e Toronto (Smart Growth America, n.d.c).

Em 2015, a Organização das Naçóes Unidas (ONU) reuniu os estados-membros e principais grupos da sociedade civil dos países para estabelecer metas com o objetivo de acabar com a pobreza, enfrentar as mudanças climáticas e buscar o desenvolvimento sustentável. Esta iniciativa foi conhecida como a Agenda 2030. Para isso, foram estabelecidos 17 objetivos de desenvolvimento sustentável (oDs) voltados principalmente para países em desenvolvimento - erradicaçáo da pobreza; fome zero e agricultura sustentável; saúde e bem-estar; educação de qualidade; igualdade de gênero; água potável e saneamento; energia limpa e acessível; trabalho decente e crescimento econômico; indústria, inovação e infraestrutura; redução das desigualdades; cidades e comunidades sustentáveis; consumo e produção responsáveis; 
ação contra a mudança global do clima; vida na água; vida terrestre; paz, justiça e instituiçóes eficazes e parcerias e meios de implementação (onu, 2015). Ainda que, inicialmente, não tenham sido explicitados oDs relacionado ao transporte sustentável, este está relacionado a vários oDs, contribuindo para o desenvolvimento das cidades inclusivas, seguras, inovadoras e sustentáveis (Portugal, 2017). Um ano após a divulgação da Agenda 2030, a onu desenvolveu um documento explicando a importância do transporte sustentável para atingir as metas estabelecidas inicialmente (onU, 2016). Estabeleceu-se a política de transporte como fundamental para alcançar as seguintes oDs: saúde e bem-estar; fome zero e agricultura sustentável; energia limpa e acessível; consumo e produção; indústria, inovação e infraestrutura; ação contra a mudança global do clima e cidades e comunidades sustentáveis. Segundo a ONU (2016), o desenvolvimento só é atingido por meio de políticas voltadas ao desenvolvimento sustentável. Tendo isto em vista, investimentos em transporte sustentável só obtêm um desenvolvimento sustentável, se for priorizada a segurança das viagens e dos modos. As ruas completas buscam a mobilidade, integração e interação dos diversos modos de transporte de forma segura, indo ao encontro com as proposiçóes da ONU (2016).

Entretanto, no Brasil e, em especial, em Natal, a quase totalidade dos processos de projetação e reprojetação viária ainda lança mão do conceito tradicional de planejamento para a fluidez automobilística em meio urbano. O carro, por sua vez, é um dos maiores sonhos de consumo da população. A “cultura do carro" já está inserida na sociedade brasileira. Isto porque, além do conforto e impressão de segurança provido pelo automóvel, a precariedade dos diversos sistemas de transporte público no país (tempo de espera acima do planejado, superlotaçáo, demora no tempo de percurso e atrasos nos horários de partida e chegada dos veículos públicos) resultam em uma baixa confiabilidade do usuário no sistema. Além disso, o carro fornece um serviço "porta a porta", o qual apenas em poucas ocasióes, é oferecido pelo transporte público coletivo. Ou seja, o automóvel promove a locomoção da origem direto para o destino requerido. Assim, por estes motivos, houve o agravamento do congestionamento nas últimas décadas. A precariedade dos serviços de transporte coletivo torna cada vez maior a exclusão social pelo transporte e agrava a saúde pública. De acordo com De Nazelle et al. (2011), a emissão de gases poluentes, o elevado número de acidentes por automóveis e a falta de atividade física causada pelo planejamento tradicional resulta em impactos na saúde pública. Assim, políticas voltadas ao transporte sustentável tendem a minimizar estes impactos devido ao aumento de atividade física e possíveis reduções de poluição do ar e sonora. Entretanto, é importante mencionar que a falta de políticas eficazes em prol do transporte sustentável pode expor o pedestre e o ciclista a inalarem mais poluentes e a terem maiores conflitos no tráfego (De Nazalle et al., 2011). Diante deste quadro, prolifera a ação de coletivos sociais em prol de maiores níveis de caminhabilidade e ciclabilidade. Este contexto deu origem a um movimento que culminou na sanção da Lei Federal 12.587/2012, conhecida como a Política Nacional de Mobilidade Urbana (Ministério das Cidades, 2013).

A Lei brasileira objetiva planejar o crescimento das cidades de forma organizada, priorizando os investimentos em sistemas de transporte público e em modos 
não-motorizados e políticas de restrição ao uso do automóvel. É de interesse avaliar que a Política brasileira foi estabelecida previamente à Agenda 2030, tendo como base iniciativas europeias neste ramo. Em 2008, o Brasil, por meio do Projeto Apoio aos Diálogos Setoriais União Europeia-Brasil, consolidou pactos sociais com a política europeia que, desde 2004, recomendou aos países da União Europeia a elaborarem planos de transporte urbano sustentável, considerando o uso do solo integrado (European Comission, 2004; Machado \& Piccinini, 2018). Em 2011, estabeleceu que os países deveriam elaborar planos de mobilidade urbana sustentáveis, substituindo os planos de transporte sustentáveis, tendo um enfoque maior nos aspectos sociais, em resultados a médio-longo prazo, abrangendo todas as dimensôes da sustentabilidade e obtendo soluçóes eficazes para os problemas relativos ao transporte (European Comission, 2011; Machado \& Piccinini, 2018; May, 2015). Assim, a Política Nacional de Mobilidade Urbana surgiu a partir da troca de experiência, aprendizado e exemplo das políticas nos países europeus voltados a planos de mobilidade urbana sustentável.

A Lei propôs que os municípios com mais de 20 mil habitantes elaborassem um Plano de Mobilidade Urbana em um prazo de três anos, ora ampliado para abril de 2019. A informação oficial é de que, até julho de 2019, menos de $10 \%$ dos municípios enquadrados na exigência legal elaboraram seus planos de mobilidade (Cidades.gov.br, 2019). Não há dúvidas de que a Política Nacional de Mobilidade Urbana é uma grande oportunidade para a mudança do paradigma das políticas de transporte nas cidades brasileiras. Entretanto, a pequena quantidade de estudos tanto acadêmicos quanto institucionais (cabe mencionar o esforço apresentado em Ministério das Cidades (2015)), a falta de recursos técnicos e financeiros, a falta de vontade política e da consciência da importância da Lei pelos gestores públicos, entre outros fatores, redundam na baixa qualidade e quantidade de planos de mobilidade elaborados até este momento (Santos \& Valença, 2016), em que a internalização dos princípios de humanização das ruas no planejamento municipal chama a atenção por sua ausência.

Nesse sentido, este trabalho objetiva proceder à comparação dos elementos da Política Nacional de Mobilidade Urbana com os princípios projetuais das ruas completas, demonstrando a viabilidade de utilizar este conceito para guiar a elaboração de planos de mobilidade urbana no Brasil no que concerne o planejamento e o projeto de infraestruturas. A concretização dessa viabilidade é testada em um projeto de reconstrução de um tramo de avenida em Natal, Rio Grande do Norte, utilizando o conceito de ruas completas, observando as normas técnicas vigentes, a Lei 12.587 , e a realidade socioeconômica e de tráfego local.

\section{A relação entre as complete streets e a Lei 12.597/2012}

O modelo tradicional de planejamento de transporte utiliza o nível de serviço como o principal avaliador de performance da via, no qual avalia o nível de atraso dos automóveis, tendo como foco apenas o fluxo deste. As ruas completas requerem que sejam utilizados níveis de serviço multimodais, reconhecendo a interrelaçáo entre os modos de transporte e os impactos negativos que avenidas largas e o aumento 
de tráfego pode ocasionar à população (Litman, 2015, 2017). A eficiência de uma abordagem multimodal do sistema de transporte acontece quando permite que usuários escolham o modo mais apropriado para cada viagem e deve ser baseado em uma análise de indicadores de acessibilidade (mobilidade dos modos de transporte, conectividade e integraçáo do sistema, e características do uso do solo) e medidas de performance do sistema de transporte (níveis de serviço multimodais, tempo de viagem per capita, e viabilidade econômica) (Litman, 2017). Segundo Elias (2011), comparando o nível de serviço multimodal de quatro modelos de vias no design tradicional e de ruas completas, concluiu-se que uma rua completa bem executada aumenta o nível de serviço do transporte sustentável, com mínimo impacto no automóvel. Sendo assim, ruas completas reduzem custos de transporte e danos ambientais, gerando uma cidade mais segura, atrativa e economicamente vibrante (Transport Canada, 2009). É importante notar que as ruas completas utilizam como base os conceitos de traffic calming, smart growth, context-oriented planning, place making e transport demand management, além de contribuir para o desenvolvimento sustentável (Hui, Saxe, Roorda, Hess, \& Miller, 2018; Litman, 2015).

Além do nível de serviço multimodal proposto por Elias (2011), um método quantitativo para avaliar o quáo completo é uma complete street nos diferentes contextos de planejamento urbano foi desenvolvido por Kingsbury, Lowry e Dixon (2011). Inicialmente se utiliza indicadores que avaliam em quatro dimensóes (automóvel, bicicleta, pedestre e transporte coletivo) a rua. A partir dos dados coletados, os indicadores são colocados em perfis de ruas que toma em conta aspectos funcionais (arterial, coletor, local) e a relevância do espaço público para a comunidade por meio de participação popular. Por último, é calculado as deficiências e a "overall completeness score" da rua analisada. Apesar deste método tomar em conta a função da rua em termos de mobilidade e de espaço público, o método peca por desconsiderar o aspecto ambiental (Hui et al., 2018). Ainda há poucos métodos quantitativos de avaliação de performance na literatura e em práticas de ruas completas, além do que, todos os métodos não tomam em conta a função ambiental da rua (Hui et al., 2018). Mesmo com muito o que propor em relação ao conceito de ruas completas, cabe notar a mudança de paradigma entre um planejamento voltado ao automóvel para um que toma em conta um planejamento ao contexto, todos os modos de transporte e a rua como um lugar.

Assim, as ruas completas propiciam a valorização do espaço público. $\mathrm{O}$ incentivo ao transporte sustentável deve ser aliado ao bom uso do espaço público para dar segurança, acessibilidade e motivação a pedestres, ciclistas e usuários de transporte público na utilização daquele espaço (Banister, 2008; Schönfeld \& Bertolini, 2017; Valença \& Santos, 2018). Por fim, já se percebeu a importância de relacionar o transporte com a economia local, pois projetos de ruas completas pensados para ampliar a quantidade de usuários do comércio, criar oportunidades de emprego e de valorizaçáo imobiliária levam ao desenvolvimento econômico (New York City DoT, 2013).

A tabela 1 evidencia a relação direta entre o conceito de ruas completas e os princípios e diretrizes da Política Nacional de Mobilidade Urbana. O fato de as complete streets terem como princípio básico a opção pelo transporte sustentável 
permite o comparativo com a Lei $12.587 / 2012$. Isto porque a Política Nacional de Mobilidade Urbana (PNMU) exige que os municípios brasileiros elaborem planos de mobilidade que efetivem políticas voltadas à mobilidade sustentável, tendo em vista o desenvolvimento socioeconômico local.

Segundo Portugal (2017), a mobilidade sustentável pode ser separada em três níveis: i) três dimensões da sustentabilidade - ambiental, social e econômico -, ii) os cinco atributos - produtiva, inclusiva, segura, justa e verde -, iii) os indicadores relacionados com os padróes de viagens avaliando e relacionando com cada atributo. Pode-se ver que o conceito de mobilidade sustentável, estabelecido por Portugal (2017), vai ao encontro com os princípios, objetivos e diretrizes da Lei 12.587, como visto na tabela 1 . Além disso, as ruas completas são desenvolvidas para o propósito de promover padróes operacionais e de viagens de forma integrada e produtiva, de incluir acessibilidade para todos os modos, promover viagens seguras, priorizar a qualidade do serviço e tempos de viagem aceitáveis para que as pessoas possam realizar atividades de lazer, comércio e trabalho, além de utilizar modos de transporte com energia limpa e incentivar a arborização (Elias, 2011; Litman, 2015; McCann, 2013; Smart Growth America, n.d.a; Transport Canada, 2009; Valença \& Santos, 2018). Portanto, as ruas completas estão não somente de acordo com as 3 dimensóes da sustentabilidade, mas também com os atributos da mobilidade sustentável e, consequentemente, a sua avaliação pode ser realizada por meio dos indicadores e podendo ser utilizadas como políticas de efetivação da Lei $12.587 / 2012$.

Em um país onde $25,7 \%$ dos municípios não possuem órgão gestor para lidar com políticas voltadas ao transporte, torna-se improvável a realização de planos de mobilidade urbana de qualidade, devido à falta de capacitação técnica dos gestores locais (Instituto Brasileiro de Geografia e Estatística [IBGE], 2012). Grande parte dos municípios brasileiros não possuem nem cidades vizinhas com técnicos capazes de auxiliar na elaboração de planos de mobilidade, dependendo assim de financiamento federal e/ou estadual para realizarem os seus respectivos planos de mobilidade (Lessa, G. Silva, L. Silva, 2015; Santos \& Valença, 2016). É importante ressaltar a iniciativa do Ministério das Cidades em iniciar cursos de capacitação técnica para elaboraçáo de planos de mobilidade urbana e gestáo de projetos aos gestores públicos (Ministerio das Cidades, 2017). Entretanto, este curso ainda é de pequena escala e centralizado nas regiôes de maior desenvolvimento econômico no país (sul-sudeste). Sendo assim, a utilização do conceito de ruas completas pode ser um caminho para aprimorar o conhecimento dos responsáveis técnicos e políticos locais. A grande quantidade de exemplos bem-sucedidos e materiais institucionais disponíveis para a implementação deste conceito pode ser um caminho para melhorar a qualidade dos planos de mobilidade no Brasil. Na seção seguinte, são expostas as caraterísticas geométricas e de uso do solo do tramo viário escolhido além dos critérios adotados e material utilizado para realizar o projeto piloto na cidade de Natal. 


\begin{tabular}{|c|c|}
\hline RUAS COMPLETAS & $\begin{array}{l}\text { POLÍTICA NACIONAL DE MOBILIDADE } \\
\text { URBANA (PNMU) }\end{array}$ \\
\hline $\begin{array}{l}\text { Infraestrutura para pedestres, com calçadas largas, } \\
\text { faixas de travessia, iluminaçâo, sinalizaçáo, conforto } \\
\text { e projetada com acessibilidade universal. }\end{array}$ & $\begin{array}{l}\text { Acessibilidade universal; desenvolvimento susten- } \\
\text { tável das cidades; segurança nos deslocamentos das } \\
\text { pessoas; prioridade dos modos não motorizados; } \\
\text { equidade e eficiência na circulação urbana e uso do } \\
\text { espaço público. }\end{array}$ \\
\hline $\begin{array}{l}\text { Infraestrutura para ciclistas, com ciclovias, ciclo- } \\
\text { faixas, bicicletários; integração com o transporte } \\
\text { coletivo. }\end{array}$ & $\begin{array}{l}\text { Desenvolvimento urbano sustentável; segurança } \\
\text { nos deslocamentos das pessoas; prioridade aos } \\
\text { modos não motorizados; equidade e eficiência na } \\
\text { circulação urbana e uso do espaço público; integra- } \\
\text { çấo entre os modos de transporte. }\end{array}$ \\
\hline $\begin{array}{l}\text { Prioridade do transporte público coletivo sobre o } \\
\text { individual; faixas exclusivas ou semiexclusivas; faci- } \\
\text { lidades de integração com o pedestre e o ciclista. }\end{array}$ & $\begin{array}{l}\text { Equidade no acesso dos cidadãos ao transporte pú- } \\
\text { blico coletivo (TPC); qualidade na prestação de ser- } \\
\text { viços do TPC; prioridade do TPC sobre o transporte } \\
\text { individual motorizado, integração entre modos e } \\
\text { serviços de transporte; priorização de projetos de } \\
\text { TPC estruturadores do território e desenvolvimento } \\
\text { integrado. }\end{array}$ \\
\hline $\begin{array}{l}\text { Arborização, facilitando a drenagem, regulação } \\
\text { da temperatura e gerando uma paisagem mais } \\
\text { agradável. }\end{array}$ & $\begin{array}{l}\text { Integração com a política de desenvolvimento ur- } \\
\text { bano e políticas setoriais de habitaçáo, saneamento } \\
\text { básico, planejamento e gestão do uso do solo no } \\
\text { âmbito dos entes federativos. }\end{array}$ \\
\hline $\begin{array}{l}\text { Medidas de traffic calming e gerenciamento de } \\
\text { tráfego com o intuito de diminuir a velocidade e } \\
\text { gerenciar o tráfego, gerando segurança ao transpor- } \\
\text { te ativo. }\end{array}$ & $\begin{array}{l}\text { Segurança nos deslocamentos das pessoas; justa } \\
\text { distribuçấo dos benefícios e ônus decorrentes do } \\
\text { uso dos diferentes modos e serviços; mitigação de } \\
\text { custos ambientais, sociais e econômicos dos deslo- } \\
\text { camentos de pessoas e cargas na cidade. }\end{array}$ \\
\hline PARA AS RUAS COMPLETAS, SMART GROW & D.A) $\mathrm{E}$ \\
\hline
\end{tabular}

TABELA I | Comparação entre elementos de uma rua completa e da Lei 12.587/2012 FONTE: ELABORAÇĀO PRÓPRIA

\section{Caracterizaçáo do tramo viário e do projeto}

Para realizar uma adequada infraestrutura para o transporte ativo, é essencial entender o seu comportamento. Primeiramente, a malha ciclo viária proposta neste trabalho tem como prioridade o ciclista que utiliza do modo como locomoçáo para o trabalho ou o comércio da rua. Para isto, é importante que as rotas sejam diretas, já que ciclovias e ciclo faixas construídas em parques, boulevards e trajetos menos diretos possuem a função de cunho recreativo (Pucher, Dill, \& Handy, 2010). Além disso, o que temos presenciado em Natal são obras muitas vezes pontuais, mal executadas e com pouca coerência logística. A maior parte das ciclovias e ciclo-faixas são desenvolvidas para ciclistas que utilizam da infraestrutura com o objetivo de lazer. Poucas ciclovias realmente são voltadas ao que utilizam do modo para ir ao trabalho, escola, faculdade, etc. Como mencionado por Valença e Santos (2018), a infraestrutura ciclo viária necessita de outros elementos estruturais além do sistema de malha para que tenha aumento no número de usuários de bicicleta. Medidas de traffic calming e gerenciamento de tráfego, instalação de bicicletários e bike sharing, 
são medidas que incentivam a utilização deste modo. Já para incentivar o pedestre, é necessário calçadas e cruzamentos com dimensionamento e acessibilidade adequados para todas as idades e habilidades, iluminação pública, drenagem, sinalização e semaforização, arborização, conexôes seguras, integração com o transporte coletivo. É também importante proporcionar passeios públicos agradáveis que incentivem o pedestre a utilizá-la com mobiliário urbano, arborização, comércios, restaurantes, obras de arte, etc. (Boston Complete Streets, 2013; Toronto Centre for Active Transportation, 2012; World Resources Institute [WRI], 2017). É importante ressaltar que o pedestre geralmente utiliza da menor distância entre dois pontos e prefere caminhar no mesmo nível, evitando passarelas ou passagens subterrâneas, que gastam mais energia, tempo e que geram insegurança (Departamento Nacional de Infraestrutura de Transportes [DNIT], 2010). Somando-se a isto, só é possível bons resultados em projetos para os modos alternativos de transporte, se forem desenvolvidos interligados com o transporte público coletivo e com infraestrutura para todos (Valença \& Santos, 2018).

As dimensóes das calçadas e das ciclovias (ver tabela 2) tiveram como base o Manual de Projeto Geométrico de Travessias Urbanas (DNIT, 2010), bem como exemplos de projetos de ruas completas já executados nas cidades de Toronto (Toronto Centre for Active Transportation, 2012) e Boston (Boston Complete Streets, 2013), escolhidos porque são referências na América do Norte de bons projetos de ruas completas e de material institucional. Note-se que as duas cidades já obtiveram prêmios em projetos de grande escala de complete streets (Brown \& Storey Architects, 2015; Utile Design, n.d). Nota-se a valorizaçáo do espaço para o pedestre nas ruas completas, com amplo espaço reservado para calçadas nesse tipo de planejamento.

\begin{tabular}{|l|c|c|c|}
\hline \multirow{2}{*}{ ELEMENTO DO ESPAÇO URBANO } & DNIT & \multicolumn{2}{|c|}{ COMPLETE STREETS } \\
\cline { 2 - 4 } & $\begin{array}{c}\text { (VALORES } \\
\text { MÍNIMOS, } \mathbf{M} \text { ) }\end{array}$ & $\begin{array}{c}\text { (VALORES } \\
\text { MÍNIMOS, } \mathbf{M} \text { ) }\end{array}$ & $\begin{array}{c}\text { (VALORES } \\
\text { MÁxIMOS, } \mathbf{M} \text { ) }\end{array}$ \\
\hline Passeio livre da calçada & 1,50 & 2,40 & 3,60 \\
\hline Faixa de segurança da calçada & 0,60 & 1,50 & 1,80 \\
\hline $\begin{array}{l}\text { Distância entre a edificação e o } \\
\text { passeio livre da Calçada }\end{array}$ & 0,60 & 0,60 & 0,60 \\
\hline Ciclovias com sentido único & 1,50 & 1,50 & 1,80 \\
\hline
\end{tabular}

TABELA 2 Critério de dimensionamento da via

FONTE: ELABORAÇẤO PRÓPRIA

Escolheu-se um tramo da Avenida Antônio Basílio - entre a Rua Jaguarari e a Av. Salgado Filho, em Natal, Rio Grande do Norte -, com um comprimento total de 1,13 $\mathrm{Km}$, para realizar o projeto de revitalização da via (figura 1). A Av. Antônio Basílio é classificada como via coletora tipo 1: as que conectam fluxos estruturais e locais do bairro (Prefeitura Municipal de Natal, 2007). A escolha se deu pelo fato de o tramo estar localizado em área central de Natal, com significativa presença de comércios e serviços. A figura 1 apresenta o tramo viário utilizado para propor a sua reprojetaçáo. 
A geometria da via foi obtida através de um mapa da cidade de Natal em AutocAD 2D, que traz medidas bem ajustadas à realidade (revelada por mediçóes amostrais de quatro seçóes, uma por segmento), além de que fornece medidas coerentes com aquelas obtidas diretamente no Google Maps. $\mathrm{O}$ tramo viário, então, foi dividido em trechos geometricamente semelhantes, como se pode ver na tabela 3. É importante observar que a grande variação de largura do canteiro central nos segmentos 1, 2 e 4 se deve a pontos de estacionamento no canteiro central ou à reduçáo do canteiro central para o retorno de veículos, quando a via operava em duplo sentido de circulação. Em outubro de 2016, houve uma mudança na gestão operacional da Av. Antônio Basílio, adotando-se a partir daí sentido único de circulação em ambos os lados do canteiro central, inutilizando-se assim os retornos (Prefeitura Municipal de Natal, 2016).

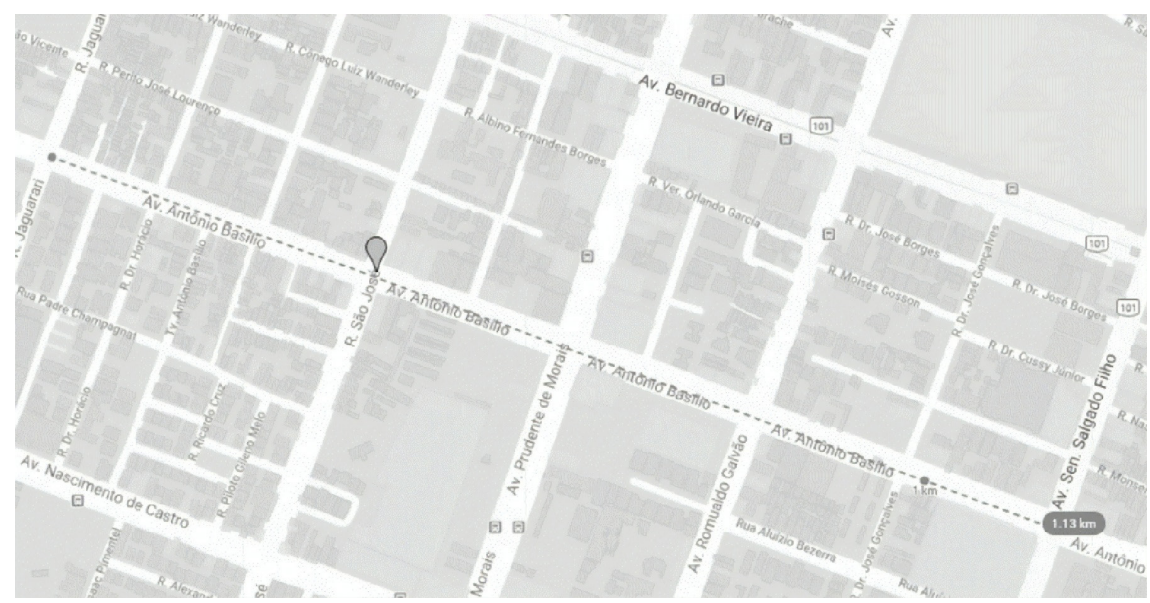

FIGURA I | Print screen do tramo utilizado no projeto

FONTE: GOOGLE MAPS

\begin{tabular}{|c|c|c|c|c|c|c|}
\hline 点 & TRECHO & $\begin{array}{c}\text { LARGURA } \\
\text { DA VIA, } \\
\text { EXCLUINDO } \\
\text { CALÇADAS }\end{array}$ & $\begin{array}{l}\text { LARGURA } \\
\text { TOTAL DA } \\
\text { VIA }\end{array}$ & $\begin{array}{l}\text { QUANTIDADE } \\
\text { DE FAIXAS DE } \\
\text { ROLAMENTO }\end{array}$ & $\begin{array}{l}\text { LARGURA DO } \\
\text { CANTEIRO } \\
\text { CENTRAL }\end{array}$ & $\begin{array}{c}\text { COMPRI- } \\
\text { MENTO } \\
\text { DA VIA }\end{array}$ \\
\hline 1 & $\begin{array}{l}\text { Av. Jaguarari - } \\
\text { Av. Prudente de Morais }\end{array}$ & $22 \mathrm{~m}$ & $27 \mathrm{~m}$ & 6 & $2,90-5,10 \mathrm{~m}$ & $575 \mathrm{~m}$ \\
\hline 2 & \begin{tabular}{|l|} 
Av. Prudente de Morais - \\
Av. Romualdo Galvão
\end{tabular} & $20 \mathrm{~m}$ & $27 \mathrm{~m}$ & 4 & $5,40-7,30 \mathrm{~m}$ & $190 \mathrm{~m}$ \\
\hline 3 & $\begin{array}{l}\text { Av. Romualdo Galvão - } \\
\text { R. José Gonçalves }\end{array}$ & $20 \mathrm{~m}$ & $26 \mathrm{~m}$ & 4 & $6,70-7,50 \mathrm{~m}$ & $160 \mathrm{~m}$ \\
\hline 4 & $\begin{array}{l}\text { R. José Gonçalves - } \\
\text { Av. Salgado Filho }\end{array}$ & $20 \mathrm{~m}$ & $25 \mathrm{~m}$ & $4-6$ & $3,60-8,50 \mathrm{~m}$ & $160 \mathrm{~m}$ \\
\hline
\end{tabular}

TABELA 3 | Caraterizaçáo geométrica do tramo escolhido

FONTE: ELABORAÇÃO PRÓPRIA 
Com o sentido único adotado na via, o canteiro central perdeu a sua função original. A pouca utilização e grande ocupação de espaço contribui para que optássemos pela retirada do canteiro central no projeto. O projeto entáo tem a proposta de retirar o canteiro central e mover a arborização para as calçadas, promovendo sombra ao pedestre. Além disso, a retirada do canteiro central gera um grande espaço para a inserção de calçadas largas, ciclovias, arborização, sem prejudicar o tráfego local.

Para a boa execução de uma rua completa, o uso da classificação tradicional da hierarquização viária (local, arterial, coletora, estrutural, etc.) não só é insuficiente, como beira a incoerência. É essencial, no caso, analisar o contexto socioeconômico do bairro e a maneira como está se utilizando o solo (Boston Complete Streets, 2013). Entáo, para o estudo do uso do solo na Av. Antônio Basílio, foi utilizado o Google Maps/Street View para identificar a quantidade e a extensão dos diferentes tipos de uso dos lotes, como se mostra na figura 2 e na tabela 4 . O mapa de ocupaçáo e uso do solo demonstra a diversidade do uso do solo no caso de estudo analisado, visualizado na figura 2. Foram identificadas tanto a quantidade de lotes de um mesmo tipo como os comprimentos das fachadas. O comprimento da testada do lote é um importante indicador porque revela a relevância do lote na avenida. Isto porque, um grande empreendimento como, por exemplo, um supermercado, só irá contar como um lote comercial, entretanto a sua área ocupada e a sua relevância no trecho são bem maiores. Como se pode observar na figura 2 e na tabela 4 , a Av. Antônio Basílio é uma rua de caráter mais comercial, com restaurantes, bares, lanchonetes, escritórios, clínicas e supermercados. No tramo e nas suas proximidades (nas transversais), encontram-se dois supermercados, um shopping center, além de três estabelecimentos de ensino - fundamental e médio, técnico e superior. Por isso, cabe que o projeto enfatize a infraestrutura para pedestres, ciclistas e usuários de transporte público, dando maiores opçóes de mobilidade para usuários de lojas comerciais e de serviços, bem como para frequentadores dos estabelecimentos de ensino.

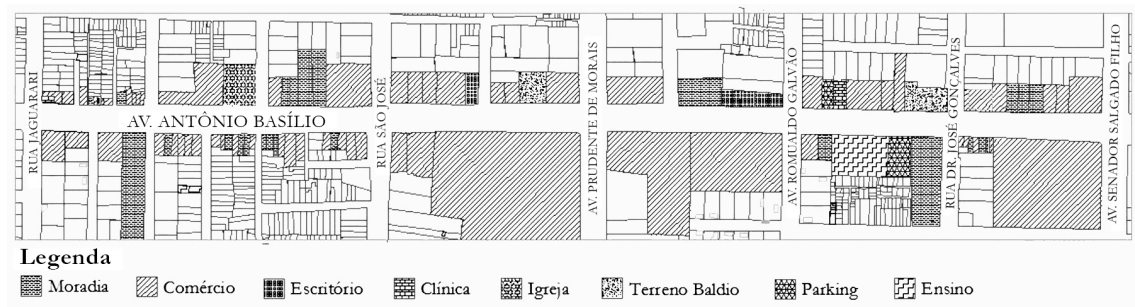

FIGURA 2 | Mapa de ocupação e uso do solo do tramo viário analisado FONTE: ELABORAÇÃO PRÓPRIA

Pode-se verificar, a partir da tabela 4, que o uso do solo predominante é comercial, com $60 \%$ dos lotes e $69 \%$ de ocupação da testada ocupada total. A testada média ocupada e ponderada pelas quantidades de lotes por tipo de uso é de 19,47 m, com essa definiçáo sendo influenciada pela maioria dos lotes comerciais, o que faz 
presumir uma intensa circulação longitudinal e transversal de pedestres. Pode-se reforçar esse elemento com a consideração de que o segundo tipo de uso do solo é o residencial unifamiliar; some-se a esta informação o fato de que as primeiras quadras das transversais, a partir da Av. Antônio Basílio, são praticamente residenciais.

\begin{tabular}{|l|c|c|c|c|c|c|c|c|c|}
\hline \multicolumn{1}{|c|}{$\begin{array}{c}\text { USO DO } \\
\text { SOLO }\end{array}$} & $\begin{array}{c}\text { MORA- } \\
\text { DIA }\end{array}$ & COMÉRCIO & $\begin{array}{c}\text { ESCRI- } \\
\text { TÓRIO }\end{array}$ & CLÍNICA & IGREJA & $\begin{array}{c}\text { TERRENO } \\
\text { BALDIO }\end{array}$ & PARKING & ENSINO & TOTAL \\
\hline $\begin{array}{l}\text { Quantidade } \\
\text { de lotes }\end{array}$ & 24 & 60 & 8 & 2 & 1 & 2 & 2 & 1 & 100 \\
\hline $\begin{array}{l}\text { Testada } \\
\text { ocupada (m) }\end{array}$ & 318 & 1340 & 60 & 25 & 35 & 73,50 & 35,50 & 60 & 1947 \\
\hline $\begin{array}{l}\text { Testada } \\
\text { mínima (m) }\end{array}$ & 5,40 & 3,95 & 3,00 & 12,40 & 35 & 27,50 & 11,70 & 60 & n.a. \\
\hline $\begin{array}{l}\text { Testada } \\
\text { máxima } \\
\text { (m) }\end{array}$ & 45,25 & 153,70 & 20,40 & 31,17 & 35 & 46 & 23,80 & 60 & n.a. \\
\hline $\begin{array}{l}\text { Testada } \\
\text { média (m) }\end{array}$ & 13,25 & 22,33 & 7,5 & 12,5 & 35 & 36,75 & 17,75 & 60 & n.a. \\
\hline
\end{tabular}

TABELA 4 | Caraterizaçáo dos tipos dos lotes no tramo escolhido

FONTE: ELABORAÇÃO PRÓPRIA

Quanto ao transporte público, existe apenas uma estação de embarque-desembarque em ônibus no tramo, próximo à esquina com a Av. Prudente de Morais, em que passam tão somente quatro linhas intermunicipais metropolitanas. Isso faz com que, no momento, não seja necessária uma faixa exclusiva para ônibus no segmento escolhido. Entretanto, a tendência é que, futuramente, haja uma mudança de itinerários em linhas intramunicipais de Natal que venham a carregar o tramo e fazer crescer os pontos de embarque de passageiros.

\section{O projeto}

A figura 3 apresenta o projeto de modificação, por segmentos, de forma que as células da esquerda contêm a situação atual e as células da direita trazem a proposta de projeto. A retirada do canteiro central, mesmo tendo a sua importância inicial em arborizar e diminuir a distância de travessia do pedestre na via, foi um importante tradeoff para permitir espaço para infraestrutura voltada ao pedestre, ciclista e usuário de transporte público coletivo. Verifica-se que transferir a arborização para as calçadas permite não somente sombra ao transporte ativo, mas também o plantio do dobro de arvores plantadas inicialmente. A ampliação das calçadas, como mencionado anteriormente, permite espaço para pessoas de todas as condiçóes físicas e de idade se movimentarem em segurança, espaço para arborizaçáo, iluminação pública, bancos, lixeiras, obras de arte, etc. 

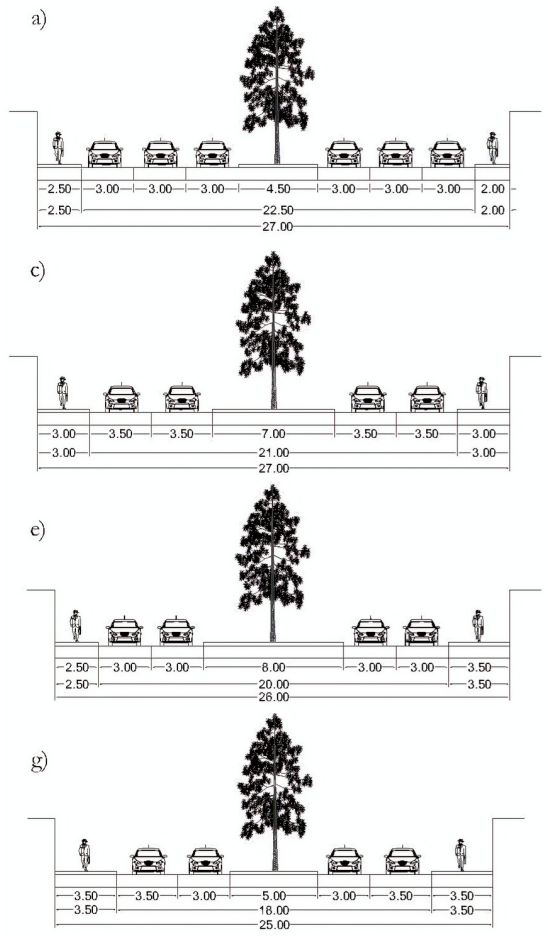

b)

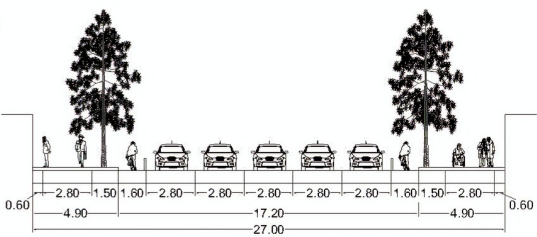

d)

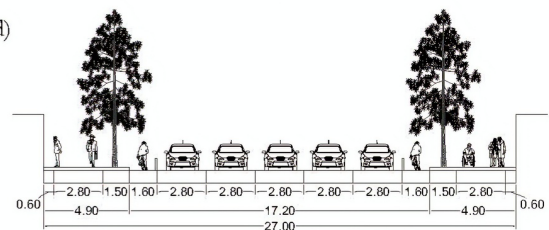

f)

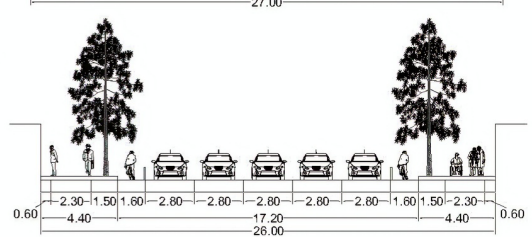

h)

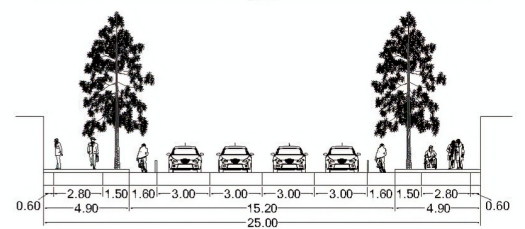

FIGURA 3 | Corte transversal dos segmentos do tramo do estado atual vs projetado. a) corte transversal do segmento 1 atual; b) corte transversal do projeto do segmento $1 ; \mathrm{c}$ ) corte transversal do segmento 2 atual; d) corte transversal do projeto do segmento 2 ;

e) corte transversal do segmento 3 atual; f) corte transversal do projeto do segmento 3 ; g) corte transversal do segmento 4 atual;

h) corte transversal do projeto do segmento 4 .

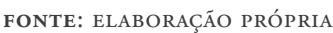

Nas ruas completas, como demostrado na figura 3, há uma valorização do espaço para o pedestre e ciclista. O aumento considerável da largura das calçadas é um importante fator a se tomar em conta no projeto de ruas completas. Inicialmente, havia uma calçada, de comprimento total de $2,50 \mathrm{~m}$ a $3,50 \mathrm{~m}$, e foi aumentado para 4,90m nos segmentos 1,2 e 4, e 4,40 m no segmento 3. A ampliação das calçadas ocasiona um passeio livre de $2,30 \mathrm{~m}$ a $2,80 \mathrm{~m}$, permitindo, no mínimo, dois cadeirantes a utilizarem este espaço com certa folga. Já a faixa de segurança da calçada entre o passeio livre e a via é importante para proporcionar maior satisfação ao pedestre, segurança e sombra em caso do uso de arborização (DNIT, 2010). O DNIT recomenda um mínimo de $60 \mathrm{~cm}$ de faixa de segurança para permitir a manutenção da calçada. Todavia, para as ruas completas este espaço é consideravelmente 
maior, tendo um mínimo de 1,50m (tabela 2), já que é um elemento essencial para incentivar o pedestre a utilizar o passeio público por meio de arborizaçáo, ajardinamento, lixeiras, bancos, exposiçóes de arte e estacionamento de bicicleta, gerando um espaço considerável de separação para os outros modos, ocasionando segurança ao pedestre, bem estar e atração para utilizar o espaço (Boston Complete Streets, 2013; Toronto Centre for Active Transportation, 2012; wRI, 2017). Por consequência, uma calçada bem projetada e com todos os elementos de incentivo e segurança propiciam um aumento de transporte ativo e valorização imobiliária no local, acarretando em incentivo ao comércio, melhor uso do solo e maior desenvolvimento econômico e sustentável do local (Litman, 2017; New York City DoT [Department of Transportation], 2013).

$\mathrm{Na}$ medida em que as interseçóes situadas na transição dos segmentos são todas semaforizadas, o que implica em uma baixa velocidade do fluxo automobilístico mesmo nas condiçôes atuais, buscou-se sempre que possível manter e até ampliar o número de faixas de rolamento em cada trecho para propiciar condiçóes de estocagem para as filas veiculares formadas nos semáforos. Isso evita que a fila se estenda até a interseção a montante do fluxo, interrompendo o fluxo transversal. Por outro lado, tendo em vista a possibilidade de implantação futura de uma faixa exclusiva, até mesmo em contrafluxo, essa opção revela-se estratégica e confere certo grau de robustez ao projeto.

Foram suprimidas no projeto quaisquer permissóes de estacionamento na rua, pressupondo-se a transferência dessa demanda para parkings ou para os recuos dos lotes comerciais. Os dois grandes supermercados existentes no tramo também contam com estacionamentos de grande porte (gratuitos sempre que haja alguma compra), com capacidade para acomodar excessos eventuais de demanda.

Por fim, cabe mencionar que o tratamento de interseçóes e dos passeios públicos para garantir comodidade e segurança aos pedestres e ciclistas também se deixou orientar pelos princípios das ruas completas e da Política Nacional de Mobilidade Urbana. Este projeto denuncia a má gestão do espaço utilizado na maioria das avenidas brasileiras, tendo apenas a visão de facilitar o fluxo de automóveis. A mudança de sentido de fluxo na Av. Antônio Basílio, realizada em 2016, foi utilizada apenas com o propósito de fornecer mais espaço para os automóveis, ainda que seja mais do que o necessário. A gestão de espaço provido para todos os usuários, proposta no projeto aqui apresentado, é importante para incentivar a descentralização dos modos de transporte. Só com uma mudança estrutural completa da via, por meio da utilização do conceito de ruas completas, do incentivo à utilização de mobiliário urbano e de implementação de outras práticas, como estacionamentos de bicicletas, bike sharing, integração com transporte coletivo, arborização e uso misto do solo, é possível vislumbrar o desenvolvimento de cidades mais humanas e vivenciáveis. Sendo assim, a rua necessita ser não somente como um espaço de locomoçáo, mas um espaço público com um importante papel econômico, social e ambiental. 


\section{Conclusóes}

A Política Nacional de Mobilidade Urbana é uma grande oportunidade para promover a evolução no modo como são tratados os espaços públicos e os sistemas locais de transportes no Brasil. Entretanto, diversas barreiras econômicas, políticas e institucionais e a falta de conhecimento e de material institucional acarretam a má qualidade e o baixo número de Planos de mobilidade já desenvolvidos. Por isto, a utilização de um conceito já bem desenvolvido, e bem-sucedido na América do Norte e em outras regióes, é uma possível solução para este dilema. Isto porque já se tem diversos projetos executados e estão disponíveis vários materiais institucionais e guias de elaboração de boa qualidade para consulta.

Este artigo demonstra por meio do projeto a viabilidade do uso de ruas completas nas cidades brasileiras. É evidente neste caso o mau uso atual do espaço urbano dedicando excessivo espaço ao automóvel, no qual resulta na falta de infraestrutura para os outros modos de transporte. Ainda que, no caso analisado, os usos do solo predominantes sejam o comercial e o residencial, o planejamento adotado atualmente não leva em conta este caráter. Por isto, as ruas completas propiciam uma melhor redistribuição do espaço urbano de acordo com as caraterísticas de demanda, o uso do solo, o caráter e o contexto socioeconômico da rua.

Os diversos benefícios das complete streets, como a valorização do espaço público, a segurança, a arborizaçáo e o incentivo a todos os modos de transportes, além do impacto socioeconômico com o aumento no número de usuários do comércio local torna a cidade mais atrativa e economicamente vibrante. Tudo isso está de acordo com os princípios, diretrizes e os objetivos da Lei da Mobilidade Urbana. Portanto, utilizar o conceito de ruas completas para orientar a elaboração dos Planos de mobilidade é um caminho, já que este conceito se enquadra nas diretrizes e princípios da Política Nacional de Mobilidade Urbana.

Finalmente, cabe mencionar que o projeto, dadas as condiçóes do trabalho, deixou de levar em conta as obrigaçóes de transparência e de participaçáo social tão caras à Lei 12.587/2012 e ao próprio conceito de ruas completas. Conquanto seja esta uma limitaçáo importante do trabalho, os autores deixam como sugestão para futuros estudos a proposiçáo de métodos de trabalho que internalizem tais exigências legais e conceituais.

\section{Referências bibliográficas}

Banister, D. (2008). The sustainable mobility paradigm. Transport Policy, 15(2), 73-80. http:// dx.doi.org/10.1016/j.tranpol.2007.10.005

Boston Complete Streets (2013). Boston Complete Streets: design guidelines. http:// bostoncompletestreets.org/pdf/2013/BCS_Guidelines.pdf.

Brown and Storey Architects (2015). St. George Street revitalization. http://www.brownandstorey. $\mathrm{com} /$ project/st-george-street-revitalization 
De Nazelle, A., Nieunwenhuijsen, M. J., Antó, J. M., Brauer, M., Briggs, D., BraunFahrlander, C. (...), \& Lebret, E. (2011). Improving health through policies that promote active travel: A review of evidence to support integrated health impact assessment. Environmental International, 37, 766-777. https://doi.org/10.1016/j. envint.2011.02.003

Departamento Nacional de Infraestrutura de Transportes (DNIT). (2010). Manual de projeto geométrico de travessias urbanas. http://ipr.dnit.gov.br/normas-e-manuais/manuais/ documentos/740_manual_projetos_geometricos_travessias_urbanas.pdf

Elias, A. (2011). Automobile-oriented or complete street? Transportation Research Record, 2257(1), 80-86. https://doi.org/10.3141/2257-09

European Commission (2004). smiLE: Sustainable Mobility Initiatives for Local Environment: towards sustainable urban transport policies: recommendations for local authorities. http://ec.europa.eu/environment/life/project/Projects/index.cfm?fuseaction=search. dspPage\&n_proj_id=1869\&docType=pdf

European Commission (2011). Impact assessment. White paper: roadmap to a single European transport area: towards a competitive and resource efficient transport system. http://www. eurosfaire.prd.fr/7pc/doc/1301988052_sec_2011_391_working_document_en.pdf

Hass-Klau, C. (1990). The pedestrian and city traffic. Londres: Belhaven Press.

Hass-Klau, C. (1992). Civilised streets: a guide to traffic calming. Londres: Environmental \& Transport Planning.

Hui, N., Saxe, S., Roorda, M., Hess, P., \& Miller, E. J. (2018). Measuring the completeness of complete streets. Transport Reviews, 38(1), 73-95. https://doi.org/10.1080/01441647 .2017 .1299815

Instituto Brasileiro de Geografia e Estatística (IBGE). (2012). Perfil dos Municípios Brasileiros. Brasília: Autor. https://ww2.ibge.gov.br/home/estatistica/economia/ perfilmunic/2012/default.shtm

Kingsbury, K. T., Lowry, M. B., \& Dixon, M. P. (2011). What Makes a "Complete Street" Complete? Transportation Research Record: Journal of the Transportation Research Board, 2245(1), 103-110. https://doi.org/10.3141/2245-13

Lei 12.587, de 3 de janeiro de 2012 (2012). Institui as diretrizes da Política Nacional de Mobilidade Urbana; revoga dispositivos dos Decretos-Leis n. ${ }^{\text {s }} 3.326$, de 3 de junho de 1941, e 5.405, de 13 de abril de 1943, da Consolidação das Leis do Trabalho (CLT), aprovada pelo Decreto-Lei n. ${ }^{\circ 5} 5.452$, de 1 o de maio de 1943 , e das Leis n. ${ }^{\text {os }} 5.917$, de 10 de setembro de 1973, e 6.261, de 14 de novembro de 1975; e dá outras providências. Brasília. 2012. http://www.planalto.gov.br/ccivil_03/_Ato20112014/2012/Lei/L12587.htm

Lessa, C., Silva, G., \& Silva, L (2015, junho). Planejamento da mobilidade urbana em municípios de pequeno porte. Anais do Congresso Brasileiro de Transporte e Trânsito. Santos, sp, Brasil, 20. http://files-server.antp.org.br/_5dotSystem/download/dcmDo cument/2015/06/15/E4F0D2FD-0B72-4882-973F-BE827EE04FA5.pdf

Litman, T. (2015). Evaluating complete streets: the value of designing roads for diverse modes, users and activities. Victoria Transport Policy Institute. http://www.vtpi.org/compstr.pdf.

Litman, T. (2017). Toward more comprehensive and multi-modal transport evaluation. Victoria Transport Policy Institute. http://www.vtpi.org/comp_evaluation.pdf. 
Machado, L. \& Piccinini, L. (2018). Os desafios para a efetividade da implementação dos planos de mobilidade urbana: uma revisão sistemática. Revista Brasileira de Gestão Urbana (URBE), 10(1), 72-94. http://dx.doi.org/10.1590/2175-3369.010.001.ao06

May, A. (2015). Encouraging good practice in the development of Sustainable Urban Mobility Plans. Case studies on Transport Policy, 3(1), 3-11. https://doi.org/10.1016/j. cstp.2014.09.001

McCann, B. (2013). Completing our streets: the transition to safety and inclusive networks. Washington: Island Press.

Ministério das Cidades (2013). Política Nacional de Mobilidade Urbana. Brasília: Autor. http://www.portalfederativo.gov.br/noticias/destaques/municipios-devem-implantarplanos-locais-de-mobilidade-urbana/CartilhaLei12587site.pdf

Ministério das Cidades (2015). Caderno de referência para elaboração de Planos de Mobilidade Urbana. Brasília: Autor. http://planodiretor.mprs.mp.br/arquivos/planmob.pdf

Ministério das Cidades (2017). Ministério das Cidades. http://www.cidades.gov.br/component/ content/article?id=4119

Ministério das Cidades (2019). Levantamento sobre a situação dos Planos de Mobilidade Urbana nos municípios brasileiros. http://www.cidades.gov.br/component/content/ article?id $=4398$

New York City DoT (2013). The economic benefit of sustainable streets. Nova Iorque: Autor. http://www.nyc.gov/html/dot/downloads/pdf/dot-economic-benefits-of-sustainablestreets.pdf

Organização das Naçôes Unidas (onu). (2015). Transforming our World: The 2030 Agenda for Sustainable Development. Nova York: Autor. https://sustainabledevelopment. un.org/content/documents/21252030\%20Agenda\%20for\%20Sustainable $\% 20$ Development\%20web.pdf

Organização das Naçôes Unidas (ONU). (2016). Mobilizing for development. Analysis and Policy Recommendations from the United Nations Secretary-General's High-Level Advisory Group on Sustainable Transport. Nova York: Autor. https://sustainabledevelopment. un.org/content/documents/2375Mobilizing\%20Sustainable\%20Transport.pdf

Portugal, L. (2017). Transporte, Mobilidade e Desenvolvimento Urbano. Rio de Janeiro: Elsevier.

Prefeitura Municipal de Natal (2007). Plano Diretor de Natal. Natal: Autor. https://natal. rn.gov.br/semurb/paginas/File/InstrOrdSearch/24_Plano_Diretor.pdf

Prefeitura Municipal de Natal (2016). Antônio Basilio e Nascimento de Castro vão funcionar no sistema de binário. http://natal.rn.gov.br/noticia/ntc-24796.html/.

Pucher, J., Dill, J., \& Handy, S. (2010). Infrastructure, programs, and policies to increase bicycling: An international review. Preventive Medicine, 50(1), 106-125. http://dx.doi. org/10.1016/j.ypmed.2009.07.028

Santos, E. \& Valença, G. (2016, novembro). Reflexôes acerca da aplicação da Lei da Política Nacional de Mobilidade Urbana e da elaboração de planos locais de mobilidade urbana no Brasil. Actas del XIX Congreso Latinoamericano de Transporte Público y Urbano (clatpu). Montevidéu, Uruguai, 19.

Schönfeld. K. \& Bertolini, L. (2017). Urban streets: Epitomes of planning challenges and opportunities at the interface of public space and mobility. Cities, 68(1), 48-55. http:// dx.doi.org/10.1016/j.cities.2017.04.012 
Smart Growth America (n.d.a). Complete streets: fundamentals. http://old.smartgrowthamerica. org/complete-streets/complete-streets-fundamentals

Smart Growth America (n.d.b). National Complete Streets Coalition. https://smartgrowthamerica. org/program/national-complete-streets-coalition/

Smart Growth America (n.d.c). Who we are. https://smartgrowthamerica.org/program/ national-complete-streets-coalition/who-we-are/.

Suzuki, H., Cervero, R., \& Iuchi, K. (2013). Transforming cities with transit. Washington, DC: The World Bank. https://doi.org/10.1596/978-0-8213-9745-9

Toronto Centre for Active Transportation (2012). Complete street by design. Toronto: Autor. https://www.tcat.ca/wp-content/uploads/2012/03/Complete-Streets-by-DesignToronto-Streets-Redesigned-for-All-Ages-and-Abilities-Single-spread.pdf

Transport Canada (2009). Complete Streets: Making Canada's roads safer for all. http:// publications.gc.ca/collections/collection_2012/tc/T41-1-72-eng.pdf

Utile Design (n.d). Boston Complete Street wins apa National Planning Award. https://www. utiledesign.com

Valença, G. \& Santos, E. (2018). O conceito de ruas completas e a infraestrutura cicloviária: A experiência de Toronto, Canadá. Espacios, 39(8), 26-33. https://www.revistaespacios. com/a18v39n08/a18v39n08p26.pdf

WRI (World Resources Institute) Brasil (2017). 8 princípios da calçada: construindo cidades mais ativas. São Paulo: Autor. https://wribrasil.org.br/pt/publicacoes/8-principios-dacalcada 